\title{
Modularization of Science Instructional in Elementary School on Fourth Grade at 1st Semester
}

\author{
Suhartono \\ State University of Malang, malang, Indonesia \\ e-mail: hart karlim@yahoo.co.id
}

\begin{abstract}
The aim of this development was to produce (1) LAC (Learning Activity Choices) instructional model through constructivist-based modularization process, (2) user's manual of validated LAC instructional model, and (3) a modeling of teaching through a video that implement LAC instructional model. The development was carried out in three stages, namely: (1) the design stage with Dick \& Carey model of the yield instructional model LAC, (2) an evaluation and revision involving review activity by experts consultant, and (3) the stage of field testing and revision to produce a prototype model of learning in the form of LAC's manual, sample lesson plans, and models through video LAC instructional model that has been validated. Stages of the development conducted through fourth grade elementary science modularization at odd semesters, resulting prototype model of learning with following characteristics. (1) LAC instructional model is an instructional process consisting of planning, implementation, and assessment of learning with a particular syntax, (2) has a specific learning method on individual learning activities (ILA), group learning activities (GLA) and classical learning activities (CLA), (3) the use of individual student worksheets (ISW) and group student worksheet (GSW), and (4) has the goal of character formation of students accompanist.
\end{abstract}

Keywords: $\quad$ Modularization of Instructional, Natural Science in Elementary School, LAC Instructional model

\section{INTRODUCTION}

Instructional as an external factor of the learning process in the people involved, therefore the manipulation of instructional should be adjusted and take into account the characteristics of students as human beings who learn [1]. Students are unique individuals who have natural characteristics as social beings and individual beings at once. Beginning and become extinct down to the facts of humanity is the way that instructional should provide services so that students can choose the required learning activities.

Constructivist theory of social interaction wants the learning process through interaction between the learners with more skilled human beings, either friends or adults, in order to change the cognitive structure [1]. Conversely, constructivist cognitive or constructivist personal theories require that cognitive structural changes are allowed to occur in terms of individual assimilation and accommodation capabilities. That is, constructivist theory requires that students carry out individual learning activities as well as social or groups learning activities [2].

The desired instructional in the standard of instructional process in Indonesia also requires that instructional by individual and group learning activities. Such a theoretical and juridical idealization has not yet been realized. Students have not been given services that are in accordance with their wishes, still treated the same for each implementation of instructional. Modularization of instructional leads to the manipulation of instructional that gives students the choice of learning activities, while implementing learning for the same topic of learning, time and class. Learning Activity Choices (LAC) instructional model is needed to accommodate this modularization result.

\section{METHODS}

Modularization of instructional is a research \& development of instructional, modularization of natural science instructional in elementary school can be classified as a model of development of conceptual instructional oriented to the product. The model of conceptual-oriented instructional development is one of the models of the development of Dick \& Carey's instructional design [3]. Adaptation was made to Dick \& Carey's design development model. Adapted to match the terms used by Dick \& Carey with terms used in the elementary school curriculum.

From the research \& development procedures implemented, at the end of the research \& 
development can be produced prototype LAC Instructional Plan, and LAC instructional model that efficient and effective. The resulting product prototype aims to improve the efficiency and effectiveness of science learning in elementary school, especially in the fourth grade of urban elementary schools. The product is a complete instructional plan along with the specified learning resources / materials and the User Guide instructional model of Learning Activity Choices (LAC), with certain specifications that are primarily an opportunity for students to select the desired learning activity.

The test of the product is carried out in 2 (two) stages, namely (1) expert consultant review phase, and (2) the phase of review and user trial in class IV SDN Jodipan Malang. The experimental design in this research \& development uses descriptive design at the first stage of expert consultant review. While the stages of reviews and user trials using quasi experimental one group pretest-posttest design.

Data collection and information of qualitative and quantitative types utilize developed instruments. Data analysis is done by qualitative analysis and quantitative analysis. For quantitative analysis used percentage analysis to determine the achievement of minimal mastery learning after application of instructional model of LAC. While t-test analysis is used to analyze the pretest - posttest score according to the test design.

Based on data and product test information, the first revision of the product draft is made according to the advice of an expert consultant. After the user reviews and trials, another revision of the revised product is the product prototype in the form of user manual of the instructional model of LAC equipped with video modeling.

\section{RESULT AND DISCUSSION}

Effective instructional models provide an opportunity for students to become active participants in the learning process, bringing students through specific sequential steps, and describing the flow of research on student learning [4]. The effectiveness of the instructional model, as well be characterized by (1) the model describes the study of how people learn, (2) has a congruence between the objectives and the planned assessment, (3) gives the students into active participants in the learning process, (4) takes the students through the steps (5) the model must have adaptability for all grade levels and a broad student distinction [4].

Theoretically effective instructional model must have these five characteristics, of course, these characteristics must also be owned by the instructional model of Learning Activity Choice. Modularization of science instructional fourth grade in SDN Jodipan Malang has resulted in instructional model of LAC. Teachers who will implement it can use the prototype of the LAC Instructional Model User Manual as a reference. Validation of LAC instructional model is done by Subject Matter Expert (SME) science in elementary school and Instructional Specialist get very valid level. Validation is also done by users (teachers and students) whose results are highly valid.

LAC instructional models have characteristics that have an effective instructional model. The LAC instructional model is based on personal constructivist/cognitive learning theory proposed by Jean Piaget, and constructivist theory of social interaction that becomes Lev Vygotsky's view. Modularization shows that the LAC instructional model examines the existence of individual learning activity (ILA) learning outcomes having significant differences with the learning outcomes of group learning activities (GLA). The effectiveness of the instructional model of LAC is also demonstrated by the validity of the construct and the validity of the content on the assessment instruments and individual student worksheets (ISW) and group student worksheet (GSW) by subject matter expert validators.

Effective LAC instructional models also provide active participation to the students to choose their own LAC provided during the exploration and elaboration of the learning content. Specific procedures that are specific sequential steps, namely 1) obtaining information about the objectives; 2) choose ILA or GLA; 3) accepting ISW or GSW; 4) implementing ILA or GLA simultaneously; 5) obtaining confirmation of instructional content from classical learning; 6) undergo culmination in the form of assessment of learning outcomes and / or presentation of individual or group learning outcomes.

The LAC instructional model also has adaptability skills for all elementary school grades, most importantly children are able to read comprehension. Reading activity is the core of learning activities on the LAC instructional model will have a positive effect on the formation of willingness and reading ability in elementary school students. The instructional model of LAC supports the Competency Standards of Elementary School graduates, namely: "Showing favorites of reading and writing. Shows the skills of listening, speaking, reading, writing, and arithmetic" [5].

Teacher competency in implementing the learning process is highly demanded in the application of the LAC instructional model, because 
classroom and students management must provide individual, group and classroom learning conditions. Teachers are also required to be creative by developing ISW and GSW every time implementing the instructional model of LAC. Teacher Competency Standards The primary / madrasah grade teachers who are teachers of primary school / madrasah mastered by teachers are sufficient to apply the instructional model of LAC. Evidently the implementing teacher who became a collaborator of research carried out the application of LAC instructional model well.

Individual Student Worksheets (ISW) and Group Student Worksheets (GSW) are utilized in the use of LAC instructional models affect the achievement of student learning outcomes. In field trials designed by researchers using ISWs and GSWs along with learning content text, it shows the posttest scores exceeding the established Minimal Mastery Learning (MML). There was also a significant difference in the mean of posttest between those who chose ILA and those who chose the GLA this indicates that LAC performed by the students can lead to the achievement of optimal learning outcomes when the characteristics of the students but can also be less optimal if one choice.

Comparison of the achievement of the pretest posttest of students when the trial can be presented in the following picture bar chart. The pretest and posttest scores of the distribution tend to be normal distribution, the lowest and highest scores differ between those who choose individual learning activities (ILA) with those who choose group learning activities (GLA).

The t test statistical results at degrees of freedom $=62$ and $\alpha=0.05$ are found to be significantly different between the mean of pretest - posttest mean and supported by the number of students who reach the MML after application of the instructional model of LAC on the topic of learning "Structure of Plant Roots and Functions". The students who succeeded in obtaining a score of more than or equal to the MML were 29 students from 32 students.

While in field trials designed by teachers using ISWs and GSWs, the content of learning utilized textbooks owned by students, there was a decrease in posttest scores achieved by students. However, this does not mean that textbooks cannot be utilized in this PAB learning model.

MML is not achieved because of 32 students, who received more than or equal to the MML of 22 students or $68.75 \%$ of the number of students. The weakness of this LAC instructional model lies in when a learning topic that requires the existence of learning must be through the activities group or individual or classical in absolute learning [6]. Instructional model of LAC not worth applying to the learning topic. As with any other instructional model, this LAC instructional model cannot be utilized for all instructional topics.

\section{CONCLUSIONS}

\subsection{Usage Advice}

The user of the instructional model of LAC is advised to do the following:

1) Read the user manual of the instructional model of LAC before starting the learning process. Understanding of sequential and specific steps is needed to achieve the effectiveness of learning through the instructional model of LAC.

2) Carefully observe the learning video utilization of the instructional model of LAC, to facilitate the utilization to be made.

3) ISWs and GSWs are made according to students' reading ability, the size of letters and narration and illustrations tailored to the characteristics of students. The learning steps written on ISWs and GSWs should be understood by the students who read them.

4) It is recommended to use the LAC instructional model at high class in grade 4-6, before utilizing for the lower classes. This is intended to familiarize the utilization to students who already have good reading skills.

5) If activities in any LAC there are learning activities that require concrete media (biotic or abiotic) is suggested to be provided by the teacher. The provision is to avoid the mistakes of the preparations required in the steps of learning activities.

\subsection{Dissemination}

The dissemination of the use of the LAC instructional model can be implemented in stages and implemented in a limited manner first. The steps taken in the framework of dissemination are as follows:

1) Socialization, ie activities to introduce the existence of instructional model of LAC through articles, seminars, training, or community service. Detailed introduction to the user's teacher to avoid misunderstanding of the concept of the instructional model of LAC.

2) Consultation, which is an activity to provide assistance to teachers of users who are 
experiencing difficulties and want to solve the problems at hand. This consultative activity is provided for the teacher of the user who inquires through e-mail account hart_karlim@yahoo.co.id.

3) Installation, which is an activity to prepare the utilization of instructional model of LAC covering the planning and tools of ISWs and GSWs. Arranging the classroom to be appropriate for ILA and GLA implementation

4) Assistance, ie activities to provide assistance to teachers of needy users to ensure the accuracy of the use of the instructional model of LAC.

5) Limited trials, ie activities to provide confidence about effectiveness and attractiveness instructional through the LAC instructional model in one class first. This step can be followed by expanding the utilization or rejecting the utilization.

\subsection{Further Product Development}

1) Development of the LAC instructional model for other lessons present in elementary schools. This can be done because the nature of the LAC instructional model is not tied to a single subject or empty technology.

2) Development of learning materials that can be used for ILA or GLA instructional material computer-based, such as interactive power points or individual and group interactive learning etc.
3) Expansion of evaluation of utilization of istructional model of LAC. Activities to improve formative evaluation for improvement are summative evaluations to determine effectiveness, efficiency and attractiveness of learning

4) Development of a simplified learning process that implements the istructional model of LAC, so as not to seem overly complex. This activity is rather difficult, but a quasi experiment simplifying the istructional model of LAC is still possible. For example, by making ISWs and GSWs that complement of textbooks or textbooks owned by the school.

\section{REFERENCES}

[1] R. Arends, Classroom Instructional Management. New York: Mc Graw-Hill Company, 1997.

[2] S.E.Smaldino, D.L. Lowther, J.D. Russell, Instructional Technology and Media for Learning. Ohio: Pearson Merrill Prentice Hall, 2008.

[3] W. Dick and L. Carey, The Systemic Design of Instruction. Glenview, Illinois: Scott, Foresman and Company, 1985.

[4] Depdiknas, Peraturan Menteri Pendiidkan Nasional Nomor 22 Tahun 2006 tentang Standar Isi. Jakarta: Depdiknas, 2006.

[5] M. A Gunter, T.H. Estes, and S.L. Mintz, Instruction A Model Approach. Boston: Pearson Education Inc, 2007.

[6] P.R. Burden and D.M. Byrd. Methods for Effective Teaching: Promoting K-12 Students Understanding. Boston: Pearson Education Inc. 2007. 